Article

\title{
Copper Oxide Chitosan Nanocomposite: Characterization and Application in Non-Enzymatic Hydrogen Peroxide Sensing
}

\author{
Antonella Arena *, Graziella Scandurra and Carmine Ciofi \\ Department of Engineering, Messina University, Messina 98166, Italy; gscandurra@unime.it (G.S.); \\ cciofi@unime.it (C.C.) \\ * Correspondence: arenaa@unime.it; Tel.: +39-90-397-7383
}

Received: 8 August 2017; Accepted: 22 September 2017; Published: 24 September 2017

\begin{abstract}
Electrochemical dissolution of metallic copper into slightly acidic aqueous solutions of chitosan yields a clear and stable dispersion of Copper Oxide nanoparticles into the organic polymer host. The electrochemically synthesized chitosan:CuOx nanocomposite is characterized by means of spectrophotometry, frequency domain electrical measurements and morphological analysis. Solid state electrochemical cells having pure chitosan as the electrolyte and using chitosan:CuOx as the electrode, are developed and characterized by means of electrical measurements performed in the $\pm 1 \mathrm{~V}$ voltage window. The current-voltage loops of the cells, measured in deionized water, are found to reversibly change in response to hydrogen peroxide added to the water in $0.2 \mu \mathrm{M}$ subsequent steps. Such changes, clearly distinguishable from changes recorded in response to other analytes, can be exploited in order to develop a hydrogen peroxide sensor able to work without the need for any supporting electrolyte.
\end{abstract}

Keywords: electrochemical sensor; chitosan; modified electrodes

\section{Introduction}

Hybrid materials, consisting of nanosized inorganic compounds dispersed into organic polymer hosts, have been the subject of renewed interest over the last few decades, owing to their facile preparation and to their potentiality in a variety of fields, going from fuel cells and supercapacitors [1,2], to photovoltaic energy generation $[3,4]$, sensing $[5,6]$, and catalysis $[7,8]$. Whenever the hybrid material has to be used in applications that involve interaction with living organisms, as is the case in the field of tissue engineering, in drugs delivery, and in food industry, the polymer host matrix is required to be biocompatible and to show no toxicity and allergenicity. All such requirements are fulfilled by chitosan [9-11]: an abundantly available biodegradable polymer, obtainable by partial deacetylation of chitin, a naturally occurring polymer found in crustacean shells, in fungal micelia and in other materials of biological origin [12]. Chitosan is a polysaccharide characterized by the presence of hydroxyl and amino functional groups in its chains. From the chemical point of view, it has the ability to interact with metal ions, organic halogen substances, and biological molecules, through a variety of mechanisms including chelation, electrostatic attraction, and ion exchange. For these reasons, chitosan has been successfully used in environmental applications, such as the removal of contaminants from wastewater [13]. In addition, chitosan is a substrate commonly used for enzymes immobilization [14]. Due to these properties, and to its ability to form stable films, insoluble in water, with good adhesion and high mechanical strength, chitosan is also an ideal candidate in sensing and biosensing applications. There are, in fact, several examples of gas [15-18] and humidity [19] sensors based on thin films of chitosan, and a wide variety of enzymatic [20-22] and enzyme-free [23-25] electrochemical sensors based on chitosan-transition metal complexes, and on chitosan dispersions of 
nanoparticles. As far as electrochemical sensing behavior is concerned, chitosan has been applied in the detection of hydrogen peroxide both in the enzymatic [26,27] and in the non-enzymatic versions [28-30]. In this paper, we demonstrate that the presence of hydrogen peroxide in water, can be successfully detected at a micromolar level by means of a solid state cell in which chitosan is used both as the polyelectrolyte that provides the electrical connection between the electrodes, and as the host polymer of the electrochemically active nanocomposite used as the electrode. Compared to other hydrogen peroxide sensors based on chitosan, the cell described here takes advantage of chitosan being used as the ion conducting bridge between the electrodes, and therefore it is able to work without the need for any kind of supporting electrolyte [31,32].

\section{Materials and Methods}

\subsection{Preparation of the Chitosan: $\mathrm{CuOx}$ Sensor}

Chitosan (medium molecular weight, purchased from Aldrich, St. Louis, MO, US), is soluble in acidic aqueous environment, where, at $\mathrm{pH}$ lower than 6.5 , the amino groups of the polymer are protonated to $\mathrm{NH}_{3}{ }^{+}$, and the polymer behaves as a cationic polyelectrolyte. Electrochemical synthesis was performed by placing two copper wire electrodes (Aldrich) inside a beaker containing $100 \mathrm{mg}$ chitosan solubilized in $150 \mathrm{~mL}$ water and acetic acid ( $\mathrm{pH}$ ranging from 5 to 6), and by applying a constant electric field between the two electrodes while the solution was agitated through a magnetic stirrer, in order to prevent the chitosan molecules from sticking on the surface of the copper cathode. Depending on the acetic acid concentration, two different kinds of electrochemical processes, involving the release of copper from the electrodes, were observed. At $\mathrm{pH}$ lower than 5.5, a pale blue hydrogel formed, similar to that obtained by Geng et al. [33], and identified by them as a copper/chitosan complex. As the electrochemical process proceeded, the pale blue solution slowly darkened, reaching the green after a few hours (Figure 1b). At pH higher than 5.5, under an applied electric field of about $5 \mathrm{~V} / \mathrm{cm}$, the copper anode started to quite rapidly consume, while the initially uncolored chitosan solution began to darken and became unclear, finally assuming a dark brown color, after a few minutes (Figure 1c).

Both the electrochemically obtained materials were used to develop electrochemical cells to be used to detect the presence of hydrogen peroxide in water. For each material, the cells were obtained as follows. We started from parallel rectangular shaped gold electrodes, spaced by half a millimeter, previously evaporated in vacuum onto copier grade transparency sheets (Tartan); a drop of the solution (either the "green" or the "brown" one) was deposited onto the top of one of the gold electrodes; after all the residual solvent evaporated, chitosan was deposited in drops in such a way as to form an ion conducting bridge between the exposed gold electrode and the one covered with the chitosan based material. A schematic view of the cell is shown in Figure $1 \mathrm{~d}$.

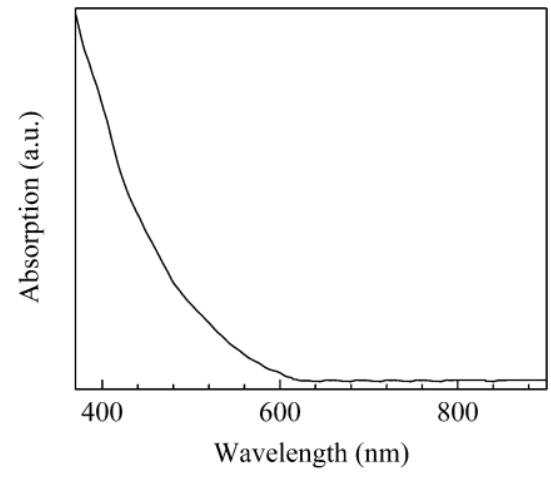

(a)

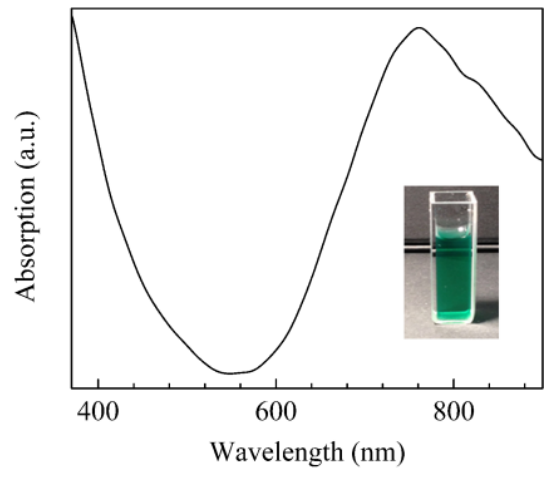

(b)

Figure 1. Cont. 


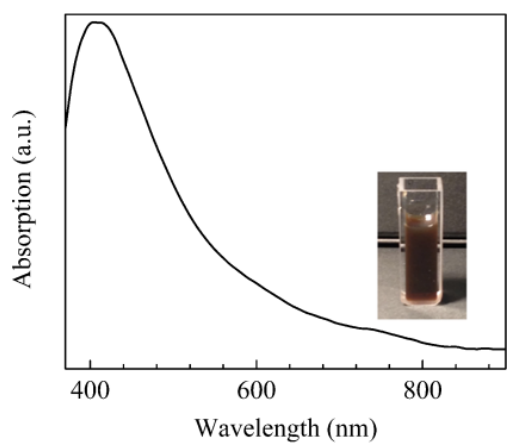

(c)

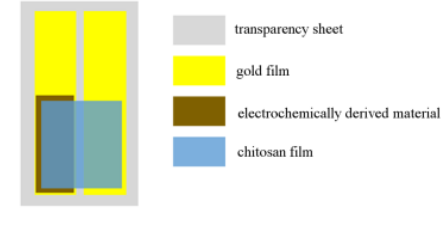

(d)

Figure 1. Absorption spectrum of the chitosan aqueous solution (a); photo and absorption spectrum of the green (b), and of the brown (c) materials electrochemically derived from copper wire electrodes immersed in chitosan solutions; (d) schematic view of the solid state cells based on chitosan.

\subsection{Characterization of Chitosan: $\mathrm{CuOx}$ Sensor}

The chitosan based materials developed as described in the previous section, were characterized by means of spectrophotometric measurements performed in the visible range by using an HR4000 microspectrophotometer (Ocean Optics, Largo, FL, US). Atomic Force Microscopy (AFM) analysis, carried out by means of a Nanosurf FlexAFM equipped with a C3000 controller (Nanosurf AG, Liestal, Switzerland), was performed to investigate the morphology of the chitosan based films, deposited from the solutions onto silicon substrates. The electrical properties of the developed materials were investigated by using impedance measurements, performed in air by means of an Agilent 4284A LCR meter (Agilent Technologies, Santa Clara, CA, US), in the frequency range between $20 \mathrm{~Hz}$ and $1 \mathrm{MHz}$, with a $100 \mathrm{mV}$ amplitude. The impedance measurements were performed on samples obtained by drop-depositing the materials from the liquid phase, onto the insulating gap between parallel gold electrodes spaced by a few hundred microns, thermally evaporated on copier grade sheets.

\subsection{Chitosan:CuOx Sensing Tests}

A 2400 source meter (Keithley, Cleveland, OH, US) was used to measure the current of the chitosan based solid state cells, in response to zero average triangular voltage inputs. Measurements were carried out at different voltage time rates, over the $\pm 1 \mathrm{~V}$ voltage windows. Sensing tests were performed in deionized water, into which hydrogen peroxide, was injected by using a micro syringe, increasing its concentration in steps of $0.2 \times 10^{-6} \mathrm{M}$. Ammonia and acetic acid where used for testing the behavior of the sensor in the presence of interferent analytes.

\section{Results and Discussion}

The electrochemically derived materials based on chitosan and copper were developed starting from chitosan acidic aqueous solutions transparent in the visible spectral range, as it is shown in the spectrum of Figure 1a. Depending on the $\mathrm{pH}$ of the chitosan acidic aqueous solution in which the electrochemical synthesis takes place, two kinds of products are obtained: the clear green solution and the dark brown suspension shown in the photos of Figure 1b,c. The nature of the two electrochemically derived products can be understood on the basis of the ability of chitosan to coordinate transition metal ions, forming metal complexes, on the condition that the $\mathrm{pH}$ of the solution in which the chemical reaction takes place meets certain requirements. It has been demonstrated that starting from copper salts dissolved in chitosan's solutions, in slightly acidic condition [34], the polymeric amine groups coordinate bivalent copper ions, forming metal complexes. On the contrary, in basic condition, these complexes do not form, and copper hydroxides precipitate. The chitosan-copper complexes exist in two configurations differing from each other by the number of amino groups that coordinate the metallic ions. Both these metallic complexes have optical absorption spectra 
characterized by the presence of a broad band, ranging from the red to the near infrared spectral interval, ascribable to $\mathrm{d}-\mathrm{d}$ electron transitions of the $\mathrm{Cu}^{2+}$ ions. Such a band is $\mathrm{pH}$ sensitive, as it is found to shift from the near infrared to the visible region, as the $\mathrm{pH}$ of the solution increases. Based on these considerations, the intense and broad absorption band, centered at about $760 \mathrm{~nm}$ in the optical absorption spectrum shown of Figure 1b, can be attributed to the copper ions, confirming that the green solution is a copper-chitosan complex. On the other side, the band at about $760 \mathrm{~nm}$ is not observed in the spectrum of the brown material, shown in Figure 1c. According to Omar et al. [35], the near infrared band ascribable to the complexation of copper with chitosan, disappears when a reducing agent is used to convert the chitosan-copper complex into chitosan, copper, and copper oxide. This consideration, and the presence of a single absorption band positioned at about $445 \mathrm{~nm}$, similar to that found by Basumallick et al. [36] and ascribed to chitosan coated copper oxides, suggest that the electrochemically synthesized brown material can be identified as chitosan dispersion of copper oxides particles. In particular, the electrochemically derived brown suspension, which from now on will be referred to as chitosan: $\mathrm{CuOx}$, is likely to be a chitosan dispersion of the red cuprous oxide $\left(\mathrm{Cu}_{2} \mathrm{O}\right)$ and the black coupric oxide $(\mathrm{CuO})$, mixed with a predominance of the former one, as the brownish color of the material suggests.

The results of AFM morphological investigations confirm the hypothesis on the nature of the electrochemically derived materials. The films deposited from the copper/chitosan complex solutions are quite smooth, as is evidenced in the upper-rightmost portion of Figure 2a. On the contrary, films obtained from the brown liquid reveal the presence of regularly shaped particles, having average size smaller than $200 \mathrm{~nm}$, as is evidenced in the AFM micrographs of Figure $2 \mathrm{~b}$.

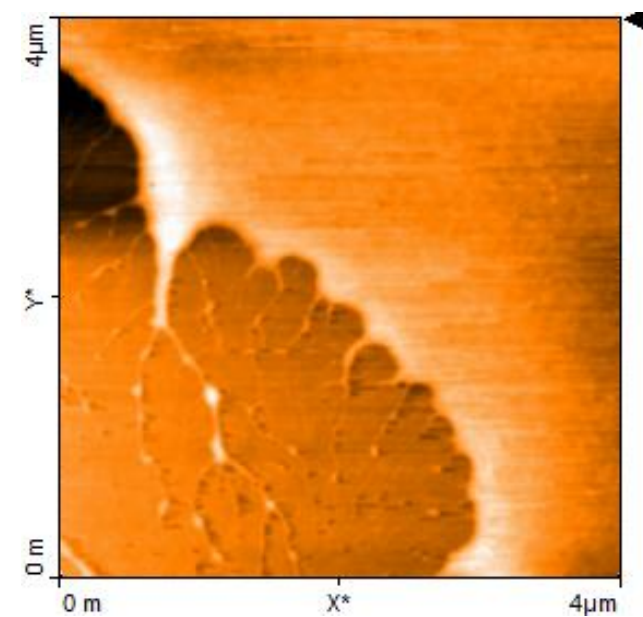

(a)

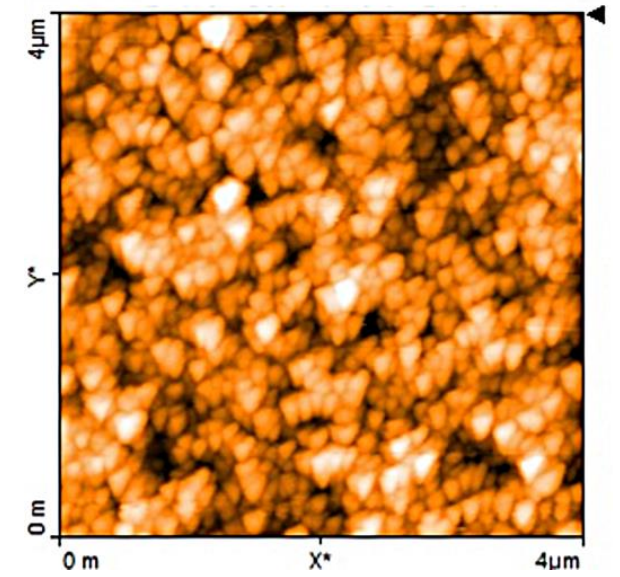

(b)

Figure 2. Atomic Force Microscopy (AFM) image close to the border of a thin film of chitosan-copper complex deposited onto a silicon substrate (visible in the bottom left portion) (a); AFM image of the chitosan:CuOx film(b).

From the electrical point of view, depending on its average molecular weight, on its crystallinity, and on its degree of acetilation, chitosan in the hydrated form behaves as an ionic conductor. Responsible for charge transport are mobile hydroxide ions that, in the presence of water, originate from the partial protonation of the amino groups bounded to the polymeric chain [36]. Figure 3 shows the Cole plot of chitosan and of chitosan:CuOx.

The opposite of the imaginary part of the impedance of chitosan, plotted versus the real one, forms a wide semicircle, as happens in the case of samples having a parallel combination of resistance, capacitance and Warburg elements as electrical equivalent. Compared to that of pure chitosan, the chitosan:CuOx Cole plot has a smaller semicircle, and therefore it is expected to have improved charge transport properties. 


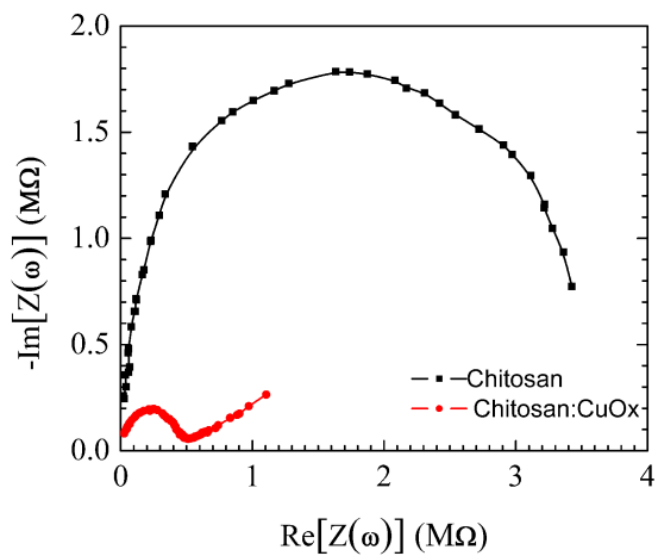

Figure 3. Opposite of the imaginary part of the impedance, plotted against the real part of the impedance, of chitosan and of chitosan:CuOx.

Figure $4 \mathrm{a}$,b shows respectively the current-voltage plot of a couple of cells developed as sketched in Figure 1c, one having the gold electrode coated with the copper/chitosan complex and the other having a chitosan: $\mathrm{CuOx}$ coated gold electrode.

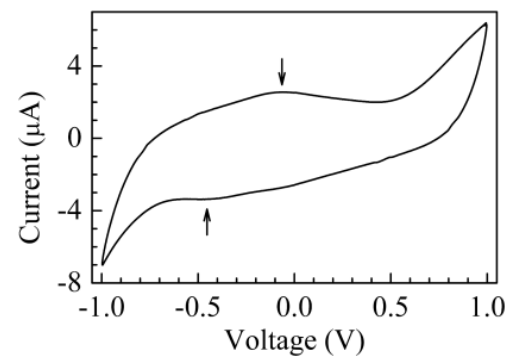

(a)

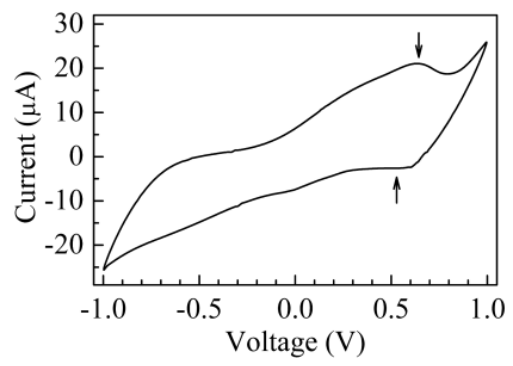

(b)

Figure 4. (a) Current-voltage loop of a cell obtained using the electrochemically derived copper-chitosan complex as the electrode; current-voltage plot of the Au/chitosan:CuOx/chitosan/Au cell (b).

The curves are obtained in deionized water, by measuring the current in response to zero average triangular voltage inputs with $40 \mathrm{~s}$ period $( \pm 50 \mathrm{mV} / \mathrm{s}$ voltage rate of change with time). After a transient phase in which the current initially grows with the increasing voltage, the current starts to cycle, forming the loops shown in Figure 4. Current loops form whenever the current is affected not only by the voltage, but also by the time rate of the voltage change: such a situation is commonly observed when dealing with capacitive-resistive systems. This may be the case in the chitosan based cells, where double layer capacitance forms at the interface between the electrode and the conducting polyelectrolyte. In addition, whenever the electrode contains electroactive species undergoing redox processes over the swept voltage range, characteristic current peaks usually arise. Observing the current-voltage plot of Figure 4a, a weak forward peak (marked by an arrow) can be noticed at about $-45 \mathrm{mV}$ and a weaker reverse peak is observed at about $-450 \mathrm{mV}$ : such a couple of peaks may be consistent with the hypothesis of redox processes involving the $\mathrm{Cu}^{2+}$ ions. Compared to that of Figure 4a, the I-V loop measured using the chitosan:CuOx modified electrode, shown in Figure 4b, has a five times larger current intensity, and exhibits a forward current peak positioned at $600 \mathrm{mV}$, approximately. A shoulder, marked by the arrow in Figure $4 \mathrm{~b}$, indicates that a reverse current peak is likely positioned between $500 \mathrm{mV}$ and $600 \mathrm{mV}$. The separation of the forward and reverse current peaks, and their intensity ratio (considerably below unity), indicate that the redox processes responsible for the peaks are irreversible. To investigate the nature of such processes, current-voltage measurements have been performed using $1 \mathrm{~V}$ amplitude triangular voltage inputs, with a different rate of change 
of voltage with time. Figure 5 a collects the results. Starting from the inner loop measured at the lowest time rate of change $( \pm 0.6 \mathrm{mV} / \mathrm{s})$, and proceeding outward (i.e., as the voltage time rate of change increases), the loops enlarge and the current peaks increase their intensity and move towards a larger voltage. Figure $5 \mathrm{~b}$ shows the intensity of the forward current peak of Figure 5a, plotted against the root square of the modulus of the voltage rate of change with time. The experimental data are distributed along a straight line, as is evidenced by the best fitting curve, indicating that a diffusion limited electrochemical process is responsible for the forward current peak. According to the results shown in Figures 4 and 5, both the chitosan complex and the chitosan:CuOx dispersions seem to be electroactive in the voltage window between $\pm 1 \mathrm{~V}$. We believe it could be of interest to investigate the possibility to exploit the solid state cells based on such materials as electrochemical sensing systems.

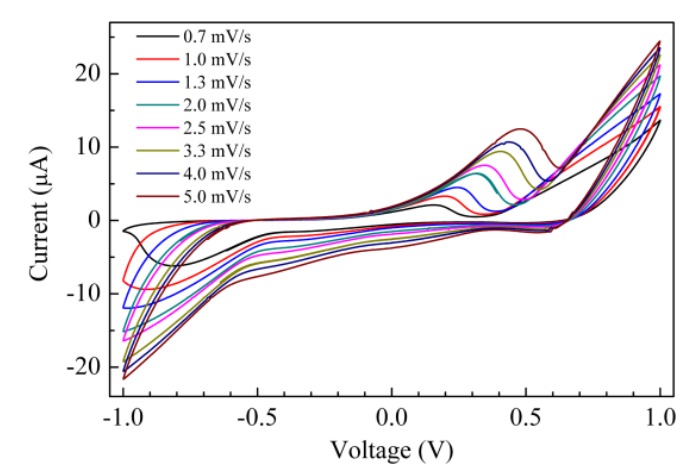

(a)

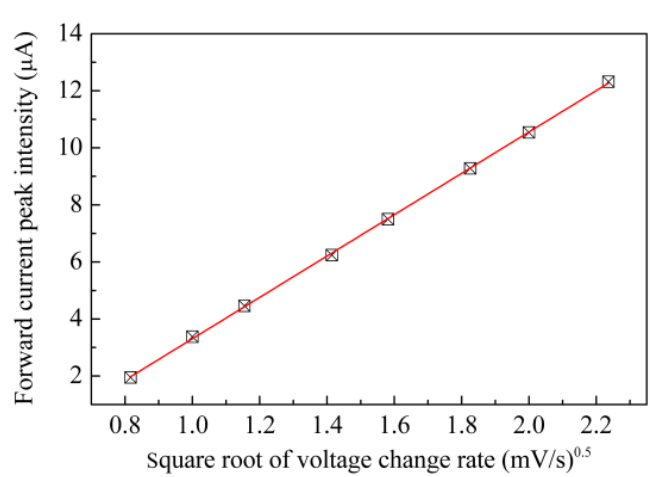

(b)

Figure 5. (a) Current-voltage loop of the Au/chitosan:CuOx/chitosan/Au cell, measured at different scan speeds; (b) Intensity of the forward current peak of Figure 5a, plotted against the square root of the scan speed.

Recently, Geng et al. [33] have shown that the presence of hydrogen peroxide in water can be detected by three electrode measurements in $0.1 \mathrm{M}$ phosphate buffer, by using a copper complex based on chitosan applied on a titanium plate as a sensitive electrode. Figure 6 shows the results of sensing tests performed by us, measuring the current-voltage loop of a typical Au/chitosan-copper complex/chitosan/Au cell into deionized water, with and without $1 \mathrm{mM}$ of hydrogen peroxide. It can be noticed that in response to $\mathrm{H}_{2} \mathrm{O}_{2}$, the loop modifies: in particular, a forward current peak (marked by an arrow in Figure 6), arises at about $500 \mathrm{mV}$. In addition, it is found that the current-voltage loop turns back to its original shape (black line in Figure 6), when the solution containing hydrogen peroxide is replaced with deionized water.

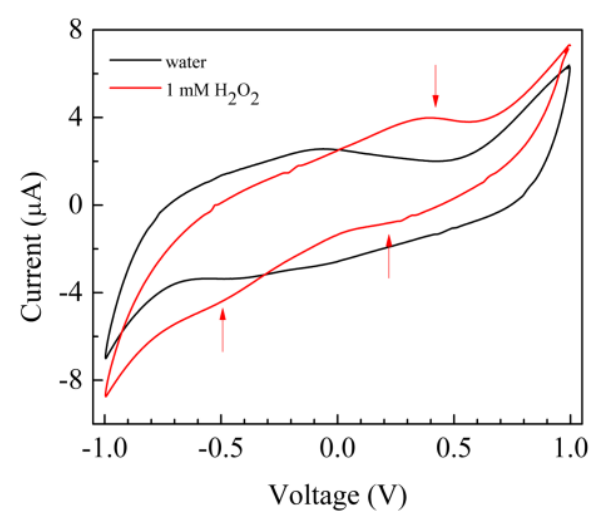

Figure 6. Current-voltage loop of the Au/chitosan-Cu-complex/chitosan/Au cell, measured in pure water, and in the presence of $0.5 \mathrm{mM}$ hydrogen peroxide. 
It can be inferred that the solid state cell schematized in Figure 1d, having the electrochemically derived chitosan-copper complex coated on the top of one of the gold electrodes, is able to detect $\mathrm{H}_{2} \mathrm{O}_{2}$ in water without the need of any supporting electrolyte, when the analyte's concentration is in the range of $10^{-3} \mathrm{M}$. Measurements performed exposing the cells to different concentrations of the analyte show that the solid state cells based on the chitosan-copper complex reversibly respond in a reproducible way to hydrogen peroxide in the millimolar range, with a limit of detection of $0.2 \mathrm{mM}$. Sensing tests performed on solid state cells having chitosan:CuOx as the active electrode, reveal that the copper oxide dispersions have higher sensitivity towards $\mathrm{H}_{2} \mathrm{O}_{2}$ compared to the copper-chitosan complex. The set of measurements of Figure $7 \mathrm{a}$ are performed by exposing a solid state cell, having chitosan: $\mathrm{CuOx}$ as the active electrode, to hydrogen peroxide at a concentration that increases in steps of $0.2 \mu \mathrm{M}$. Unexpectedly, however, starting from the current-voltage loop measured in pure water, the reverse current progressively decreases and the original forward current peak rapidly weakens as the hydrogen peroxide concentration increases. In particular, the intensity of the forward current peaks, plotted against the hydrogen peroxide concentration, as shown in Figure $7 \mathrm{~b}$, decreases in a linear way with a slope of about $1 \mu \mathrm{A}$ per $0.1 \mu \mathrm{M}$ of $\mathrm{H}_{2} \mathrm{O}_{2}$. On the contrary, according to the scientific literature, electrochemical measurements carried out in the presence of supporting electrolytes show that sensors based on graphite and glassy carbon electrodes modified with copper oxide nanoparticles [37-39], and with nanosized copper oxide dispersed into mixtures of multiwalled carbon nanotubes and chitosan [40], do respond to increasing amounts of hydrogen peroxide with an increasing current.

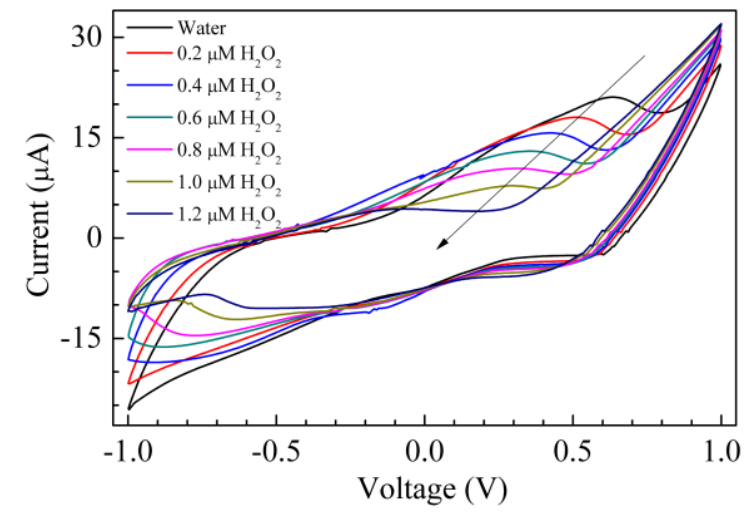

(a)

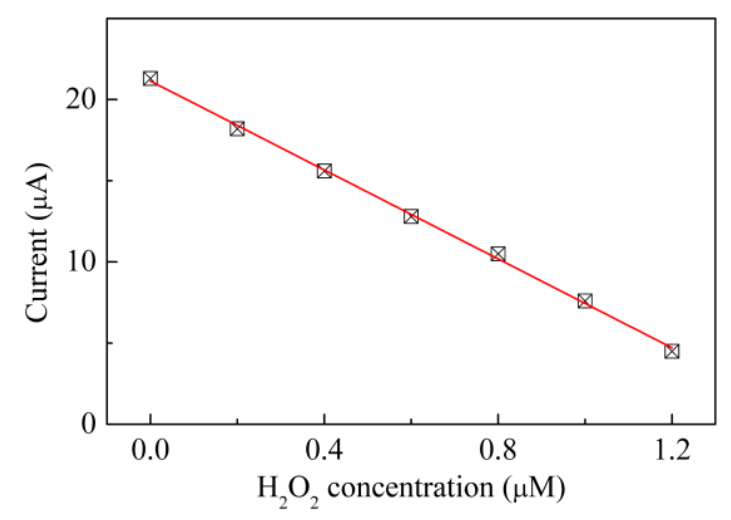

(b)

Figure 7. (a) Current-voltage loop of the Au/chitosan:CuOx/chitosan/Au cell, measured in water, and in the presence of hydrogen peroxide at different concentrations; (b) Intensity of the forward current peak intensities of Figure 7a, plotted against the $\mathrm{H}_{2} \mathrm{O}_{2}$ concentration.

The experimentally observed behavior of Figure 7 suggests that somehow the electrochemically derived chitosan: $\mathrm{CuOx}$, applied to the top of the gold electrode, as schematized in Figure 1d, does interact with $\mathrm{H}_{2} \mathrm{O}_{2}$, but the way in which this interaction manifests itself is a sort of reversible quenching of the electroactivity of chitosan:CuOx.

Aimed at evaluating the behavior of the $\mathrm{Au} /$ chitosan:CuOx/chitosan/Au cells towards analytes other than $\mathrm{H}_{2} \mathrm{O}_{2}$, sensing tests have been carried out in the presence of a base and of a weak acid, namely ammonia and acetic acid. The results are shown in Figures 8 and 9 respectively. It can be noticed that in both cases the forward current peak found at about $600 \mathrm{mV}$ in the current-voltage loop of $\mathrm{Au} /$ chitosan:CuOx/chitosan/Au in water disappears and new current peaks, the positions of which depend on the analyte, arise. In particular, Figure 8a shows that when exposed to ammonia in the micromolar range, the current-voltage loops of the $\mathrm{Au} /$ chitosan:CuOx/chitosan/ $\mathrm{Au}$ cells enlarge, and a forward current peak arises, the intensity of which is linearly related to the ammonia concentration, as the results of Figure $8 \mathrm{~b}$ suggest. In the presence of acetic acid, as is illustrated in Figure $9 \mathrm{a}$, a couple of forward and reverse current peaks arise, and again, according to the results 
shown in Figure 9b, the intensity of the forward current peak is found to be linearly related to the acetic acid concentration. In both the examined cases, the observed modification is reversible, as after a transient time the current-voltage loops turn back to their original shape and intensity by immersing the cells in deionized water. These latter results, being the investigated analytes a base and a weak acid, could be explained in terms of the $\mathrm{pH}$ sensitivity of nanosized copper oxide [41], which may persist when the material is dispersed in the chitosan host and used in the solid state cell configuration of Figure 1d.

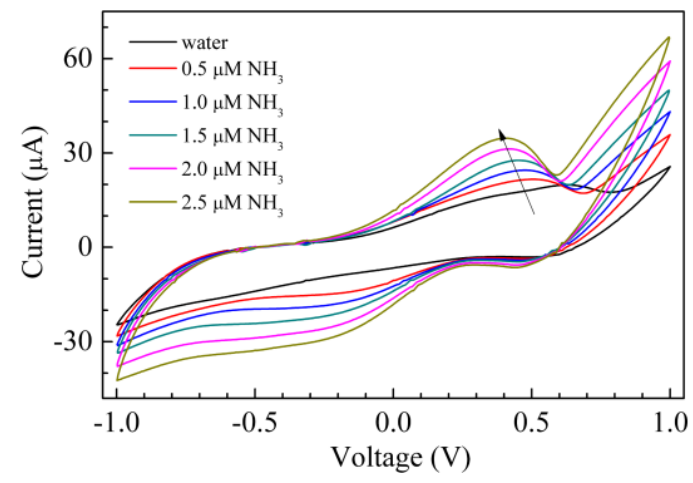

(a)

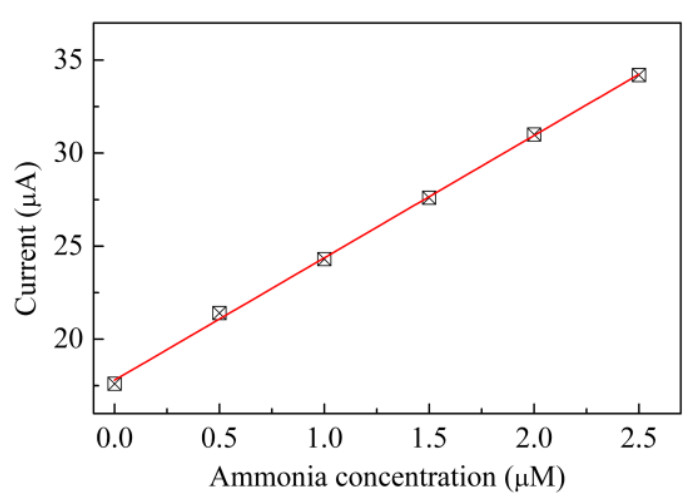

(b)

Figure 8. (a) Current-voltage loop of the Au/chitosan:CuOx/chitosan/Au cell, measured in pure water, and in the presence of ammonia at different concentrations; (b) Intensity of the forward current peak intensities of Figure (a), plotted against the $\mathrm{NH}_{3}$ concentration.

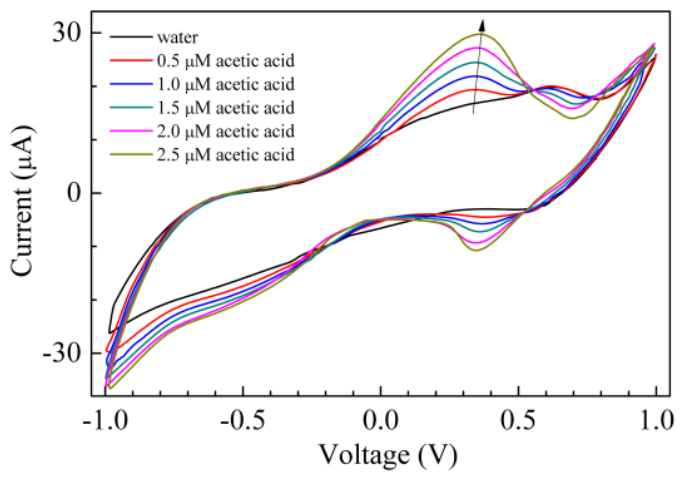

(a)

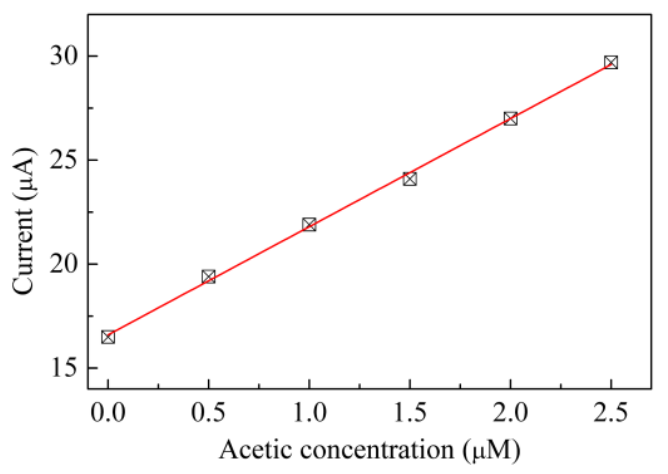

(b)

Figure 9. (a) Current-voltage loop of the Au/chitosan:CuOx/chitosan/Au cell, measured in pure water, and in the presence of acetic acid at different concentrations; (b) Intensity of the forward current peak intensities of Figure 9a, plotted against the acetic acid concentration.

The fact that in the case of $\mathrm{H}_{2} \mathrm{O}_{2}$ the amplitude of the peaks is decreasing for increasing concentration while the opposite occurs in the case of a weak acid and a base, can be used to discriminate the presence of hydrogen peroxide with respect to other species. With regard to the feasibility of employing the investigated structure for the realization of an $\mathrm{H}_{2} \mathrm{O}_{2}$ sensor, we must observe that, clearly, the fact that the response decreases with increasing concentration sets an upper limit to the maximum detectable concentration and, hence, to the dynamic range. This possible disadvantage is partially compensated by the high sensitivity that is observed at lower concentrations, as summarized in Table 1. 
Table 1. Sensitivity of the Au/chitosan:CuOx/chitosan/Au cell towards $\mathrm{H}_{2} \mathrm{O}_{2}$, compared to that of other electrochemical sensors.

\begin{tabular}{|c|c|c|}
\hline Sensor & $\begin{array}{c}\text { Sensitivity } \\
\left(\mu \mathrm{A} \cdot \mathrm{mM}^{-1} \mathrm{~cm}^{-2}\right)\end{array}$ & Ref. \\
\hline $\mathrm{Au} /$ chitosan:CuOx/chitosan/Au & 10,000 & This work \\
\hline $\begin{array}{l}\text { Glassy carbon electrode modified with copper nanoparticles decorated } \\
\text { silver nanoleaves }\end{array}$ & 6190 & [42] \\
\hline Glassy carbon electrode modified with FeS nanosheets & 36.4 & [43] \\
\hline $\begin{array}{c}\text { Carbon paste electrode modified } \mathrm{Ni}-\mathrm{Al} / \text { layered double } \\
\text { hydroxide/Ag nanoparticles }\end{array}$ & 1.836 & [44] \\
\hline Glassy carbon electrode modified with Ag@C core-shell nanomaterials & 22.94 & [45] \\
\hline Graphene oxide electrode modified with Binary Mn-Co Oxides & 53.65 & [46] \\
\hline
\end{tabular}

\section{Conclusions}

It is demonstrated that solid state cells with simple design, having electrochemically derived materials based on copper and chitosan applied to the top of one gold electrode, can be successfully used to detect the presence of hydrogen peroxide in water, at concentrations below $1 \mu \mathrm{M}$, without the need of any supporting electrolyte. While characterized by high sensitivity, the cells using chitosan: $\mathrm{CuOx}$ dispersions are found to respond to the presence of $\mathrm{H}_{2} \mathrm{O}_{2}$ with a decreasing current, unlike other conventional electrochemical sensors based on nanosized copper oxides. The difference between the two kinds of behavior can be likely ascribed to the fact that copper oxide still mantaints its electroactivity towards $\mathrm{H}_{2} \mathrm{O}_{2}$ but the way in which the material responds to the analyte is affected by the absence of a supporting electrolyte.

Author Contributions: This paper is the result of a strong collaborative effort among all authors. Antonella Arena and Graziella Scandurra designed the study and performed most of the experimental work. Carmine Ciofi contributed in the discussion of the experimental data. All authors were involved in the writing and argumentation of the paper and approved the final version of the manuscript.

Conflicts of Interest: The authors declare no conflict of interests.

\section{References}

1. Tripathi, B.P.; Shahi, V.K. Organic-inorganic nanocomposite polymer electrolyte membranes for fuel cell applications. Prog. Polym. Sci. 2011, 36, 945-979. [CrossRef]

2. Romero, P.G.; Chojak, M.; Cuentas-Gallegoa, K.; Asensio, J.A.; Kulesza, P.J.; Casañ-Pastor, N.; Lira-Cantú, M. Hybrid organic-inorganic nanocomposite materials for application in solid state electrochemical supercapacitors. Electrochem. Commun. 2003, 5, 149-153. [CrossRef]

3. Liu, R. Hybrid Organic/Inorganic Nanocomposites for Photovoltaic Cells. Materials 2014, 7, $2747-2771$. [CrossRef] [PubMed]

4. Bouclé, J.; Ravirajan, P.; Nelson, J. Hybrid polymer-metal oxide thin films for photovoltaic applications. J. Mater. Chem. 2007, 17, 3141-3153. [CrossRef]

5. Grover, R.; Nanda, O.; Gupta, N.; Saxena, K. Hydrogen peroxide sensing properties of $\mathrm{PVA} / \mathrm{TiO}_{2} / \mathrm{I}_{2}$ nanocomposite-based free standing membranes. J. Appl. Polym. Sci. 2015, 132, 42257. [CrossRef]

6. Wang, S.; Kang, Y.; Wang, L.; Zhang, H.; Wang, Y.; Wang, Y. Organic/inorganic hybrid sensors: A review. Sens. Actuators Chem. B 2013, 182, 467-481. [CrossRef]

7. Chen, J.-Y.; Zhou, P.-J.; Li, J.-L.; Wang, Y. Studies on the photocatalytic performance of cuprous oxide/chitosan nanocomposite activated by visible light. Carbohydr. Polym. 2008, 72, 128-132. [CrossRef]

8. Sarkar, S.; Guibal, E.; Quignard, F.; SenGupta, A.K. Polymer-supported metals and metal oxide nanoparticles: Synthesis, characterization, and applications. J. Nanopart. Res. 2012, 14, 715. [CrossRef]

9. Croisier, F.; Jérôme, C. Chitosan-based biomaterials for tissue engineering. Eur. Polym. J. 2013, 49, 780-792. [CrossRef]

10. Francis Suh, J.-K.; Matthew, H.W.T. Application of chitosan-based polysaccharide biomaterials in cartilage tissue engineering: A review. Biomaterials 2000, 21, 2589-2598. [CrossRef] 
11. Salih, E.; Reicha, F.M.; El-Sherbiny, I.M. Electrochemical Synthesis of New Silver-Chitosan/Polyvinyl Alcohol Hybrid Nanoparticles and Evaluation of Their Antibacterial Activities. J. Nanosci. Nanotechnol. 2016, 2, 94-96.

12. Zargar, V.; Asghari, M.; Dashti, A. A Review on Chitin and Chitosan Polymers: Structure, Chemistry, Solubility, Derivatives, and Applications. ChemBioEng Rev. 2015, 2, 204-226. [CrossRef]

13. Lalov, I.G.; Guerginov, I.I.; Krysteva1, M.A.; Fartsov, K. Treatment of waste water from distilleries with chitosan. Water Res. 2000, 34, 1503-1506. [CrossRef]

14. Biró, E.; Németh, Á.S.; Sisak, C.; Feczkó, T.; Gyenis, J. Preparation of chitosan particles suitable for enzyme immobilization. J. Biochem. Biophys. Methods 2008, 70, 1240-1246. [CrossRef] [PubMed]

15. $\mathrm{Hu}, \mathrm{X}$. An Optical Fiber $\mathrm{H}_{2} \mathrm{O}_{2}$-Sensing Probe Using a Titanium(IV) Oxyacetylacetonate Immobilized Nafion Coating on an Bent Optical Fiber Probe. IEEE Sens. J. 2011, 11, 2032-2036. [CrossRef]

16. Yoon, S.H.; Jeong, W.T.; Kim, K.C.; Kim, K.J.; Oh, M.C.; Lee, S.M. Development of the Biopolymeric Optical Planar Waveguide with Nanopattern. J. Surf. Eng. Mater. Adv. Technol. 2011, 1, 56-61. [CrossRef]

17. Fen, Y.W.; Yunus, W.M.M. Utilization of Chitosan-Based Sensor Thin Films for the Detection of Lead Ion by Surface Plasmon Resonance Optical Sensor. IEEE Sens. J. 2013, 13, 1413-1418. [CrossRef]

18. Nasution, T.I.; Nainggolan, I.; Hutagalung, S.D.; Ahmad, K.R.; Ahmad, Z.A. The sensing mechanism and detection of low concentration acetone using chitosan-based sensors. Sens. Actuators Chem. B 2013, 177, 522-528. [CrossRef]

19. Murray, C.A.; Dutcher, J.R. Effect of Changes in Relative Humidity and Temperature on Ultrathin Chitosan Films. Biomacromolecules 2006, 12, 3460-3465. [CrossRef] [PubMed]

20. Hernández-Ibáñez, N.; García-Cruz, L.; Montiel, V.; Foster, C.W.; Banks, C.E.; Iniesta, J. Electrochemical lactate biosensor based upon chitosan/carbon nanotubes modified screen-printed graphite electrodes for the determination of lactate in embryonic cell cultures. Biosens. Bioelectron. 2016, 77, 1168-1174. [CrossRef] [PubMed]

21. Kang, X.; Wang, J.; Wu, H.; Aksay, I.A.; Liu, J.; Lin, Y. Glucose-Oxidase-graphene-chitosan modified electrode for direct electrochemistry and glucose sensing. Biosens. Bioelectron. 2009, 25, 901-905. [CrossRef]

22. Wang, G.; Xu, J.J.; Ye, L.H.; Zhu, J.J.; Chen, H.Y. Highly sensitive sensors based on the immobilization of tyrosinase in chitosan. Bioelectrochemistry 2002, 57, 33-38. [CrossRef]

23. Mao, A.; Li, H.; Jin, D.; Yu, L.; Hu, X. Fabrication of electrochemical sensor for paracetamol based on multi-walled carbon nanotubes and chitosan-copper complex by self-assembly technique. Talanta. 2015, 144, 252-257. [CrossRef] [PubMed]

24. Dehdashtian, S.; Gholivand, M.B.; Shamsipur, M.; Kariminia, S. Construction of a sensitive and selective sensor for morphine using chitosan coated Fe3O4 magnetic nanoparticle as a modifier. Mater. Sci. Eng. C 2016, 58, 53-59. [CrossRef] [PubMed]

25. Rovina, K.; Siddiquee, S. Electrochemical sensor based rapid determination of melamine using ionic liquid/zinc oxide nanoparticles/chitosan/gold electrode. Food Cont. 2016, 59, 801-808. [CrossRef]

26. Wang, H.S.; Pan, Q.X.; Wang, G.X. A Biosensor Based on Immobilization of Horseradish Peroxidase in Chitosan Matrix Cross-linked with Glyoxal for Amperometric Determination of Hydrogen Peroxide. Sensors 2005, 5, 266-276. [CrossRef]

27. Yalçıner, F.; Çevik, E.; Şenel, M.; Baykal, A. Development of an Amperometric Hydrogen Peroxide Biosensor based on the Immobilization of Horseradish Peroxidase onto Nickel Ferrite Nanoparticle-Chitosan Composite. Nano-Micro Lett. 2011, 3, 91-98. [CrossRef]

28. Jiang, Y.; Li, Y.; Li, Y.; Li, S. A sensitive enzyme-free hydrogen peroxide sensor based on a chitosan-graphene quantum dot/silver nanocube nanocomposite modified electrode. Anal. Methods 2016, 8, 2448-2455. [CrossRef]

29. Jia, N.; Huang, B.; Chen, L.; Tan, L.; Yao, S. A simple non-enzymatic hydrogen peroxide sensor using gold nanoparticles-graphene-chitosan modified electrode. Sens. Actuators Chem. B 2014, 195, 165-170. [CrossRef]

30. Miao, Z.; Zhang, D.; Chen, Q. Non-enzymatic Hydrogen Peroxide Sensors Based on Multi-wall Carbon Nanotube/Pt Nanoparticle Nanohybrids. Materials 2014, 7, 2945-2955. [CrossRef] [PubMed]

31. Scandurra, G.; Arena, A.; Ciofi, C.; Saitta, G. Electrical Characterization and Hydrogen Peroxide Sensing Properties of Gold/Nafion:Polypyrrole/MWCNTs Electrochemical Devices. Sensors 2013, 13, 3878-3888. [CrossRef] [PubMed] 
32. Scandurra, G.; Arena, A.; Ciofi, C.; Saitta, G.; Lanza, M. Electrochemical Detection of p-Aminophenol by Flexible Devices Based on Multi-Wall Carbon Nanotubes Dispersed in Electrochemically Modified Nafion. Sensors 2014, 14, 8926-8939. [CrossRef] [PubMed]

33. Geng, Z.; Wang, X.; Guo, X.; Zhang, Z.; Chen, Y.; Wang, Y. Electrodeposition of chitosan based on coordination with metal ions in situ-generated by electrochemical oxidation. J. Mater. Chem. B 2016, 4, 3331-3338. [CrossRef]

34. Rhazi, M.; Desbrières, J.; Tolaimate, A.; Rinaudo, M.; Vottero, P.; Alagui, A. Contribution to the study of the complexation of copper by chitosan and oligomers. Polymer 2002, 43, 1267-1276. [CrossRef]

35. Omar, F.A.; El-Tonsy, M.M.; Oraby, A.H.; Reicha, F.M. Copper and Copper Oxides Nanoparticles Synthesized by Electrochemical Technique in Chitosan Solution. Inter. J. Sci. Eng. Appli. 2016, 3, 180-187. [CrossRef]

36. Basumallick, S.; Santra, S. Chitosan coated copper-oxides nano particles: A novel electro-catalyst for $\mathrm{CO}_{2}$ reduction. RSC Adv. 2014, 4, 63685-63690. [CrossRef]

37. Yang, G.; Chen, F.; Yang, Z. Electrocatalytic Oxidation of Hydrogen Peroxide Based on the Shuttlelike Nano-CuO-Modified Electrode. Inter. J. Electrochem. 2012, 194183. [CrossRef]

38. Kamyabi, M.A.; Hajari, N. Low Potential and Non-Enzymatic Hydrogen Peroxide Sensor Based on Copper Oxide Nanoparticle on Activated Pencil Graphite Electrode. J. Braz. Chem. Soc. 2016, 28, 808-818. [CrossRef]

39. Zhang, L.; Yuan, F.; Zhang, X.; Yang, L. Facile synthesis of flower like copper oxide and their application to hydrogen peroxide and nitrite sensing. Chem. Cent. J. 2011, 5, 75. [CrossRef] [PubMed]

40. Annamalai, S.K.; Palani, B.; Pillai, K.C. Highly stable and redox active nano copper species stabilized functionalized-multiwalled carbon nanotube/chitosan modified electrode for efficient hydrogen peroxide detection. Colloids Surf. A Physicochem. Eng. Asp. 2012, 395, 207-216. [CrossRef]

41. Zaman, S.; Asif, M.H.; Zainelabdin, A.; Willander, M. CuO nanoflowers as an electrochemical $\mathrm{pH}$ sensor and the effect of $\mathrm{pH}$ on the growth. J. Electroanal. Chem. 2011, 662, 421-425. [CrossRef]

42. Devasenathipathy, R.; Liu, Y.-X.; Yang, C.; Kohilarany, K.; Wang, S.-F. Simple electrochemical growth of copper nanoparticles decorated silver nanoleaves for the sensitive determination of hydrogen peroxide in clinical lens cleaning solutions. Sens. Actuators Chem. B 2017, 252, 862-869. [CrossRef]

43. Jin, J.; Wu, W.; Min, H.; Wu, H.; Wang, S.; Ding, Y.; Yang, S. A glassy carbon electrode modified with FeS nanosheets as a highly sensitive amperometric sensor for hydrogen peroxide. Microchem. Acta. 2017, 184, 1389-1396. [CrossRef]

44. Habibi, B.; Azhar, F.F.; Fakkar, J.; Rezvani, Z. Ni-Al/layered double hydroxide/Ag nanoparticle composite modified carbon-paste electrode as a renewable electrode and novel electrochemical sensor for hydrogen peroxide. Anal. Methods 2017, 9, 1956-1964. [CrossRef]

45. Sheng, Q.; Shen, Y.; Zhang, J.; Zheng, J. Ni doped Ag@C core-shell nanomaterials and their application in electrochemical $\mathrm{H}_{2} \mathrm{O}_{2}$ sensing. Anal. Methods 2017, 9, 163-169. [CrossRef]

46. Li, S.J.; Xing, Y.; Yang, H.Y.; Huang, J.Y.; Wang, W.T.; Liu, R.T. Electrochemical Synthesis of a Binary Mn-Co Oxides Decorated Graphene Nanocomposites for Application in Nonenzymatic $\mathrm{H}_{2} \mathrm{O}_{2}$ Sensing. Int. J. Electrochem. Sci. 2017, 12, 6566-6576. [CrossRef]

(C) 2017 by the authors. Licensee MDPI, Basel, Switzerland. This article is an open access article distributed under the terms and conditions of the Creative Commons Attribution (CC BY) license (http://creativecommons.org/licenses/by/4.0/). 